\title{
Diphtheria and Tetanus Antibody Persistence in Indian Pre-school Children and Response to a Booster dose of DT Vaccine
}

\author{
Ajit M. Satwekar ${ }^{1}$, Shireen S. Telang ${ }^{2}$, Nilesh A. Ghorpade ${ }^{1}$, Prajakt J. Barde ${ }^{3}$, \\ Moreshwar R. Patwardhan ${ }^{3}$, Prasad S. Kulkarni ${ }^{3^{*}}$

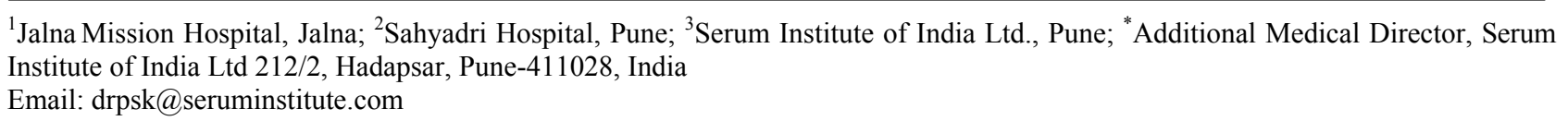

Received January $7^{\text {th }}, 2011$; revised February $20^{\text {th }}, 2011$; accepted February $21^{\text {st }}, 2011$.

\begin{abstract}
Despite effective vaccines, diphtheria $(D)$ resurged recently in the former socialistic block, and tetanus $(T)$ still occurs in less privileged countries. We studied the antibody persistence for $D$ and $T$ in Indian pre-school children who had received four doses of DTP vaccine and subsequently, the response to a booster dose. Anti-D and anti-T IgG antibodies prior to and one month after a DT vaccine were measured by ELISA in 223 healthy children of 4-6 years who had previously received four doses of the triple vaccine. Adverse reactions were monitored for one month. While $30 \%$ and $14 \%$ of subjects were susceptible to D and T, respectively, $98 \%$ and $100 \%$ of them attained seroprotection post-vaccination. Both responses were significant. Local, but not systemic reactions except fever were rather common. A high proportion of the Indian pre-school population is susceptible to $D$ and $T$, despite of receiving four doses. The current policy of giving the fifth dose at this age is appropriate.
\end{abstract}

Keywords: Diphtheria, Tetanus, Antibodies, India, Preschool Children, DT Vaccine

\section{Introduction}

Recent epidemics of diphtheria in successor countries of the former Soviet Union have drawn attention to this once forgotten disease [1,2]. Also reports from developing countries suggest changes in the epidemiology of this disease, as now diphtheria occurs in outbreaks with high case fatality rates and complications [3].

The incidence of tetanus has decreased considerably in industrialized countries, but it remains rather common in many developing countries where the heaviest burden is borne by neonates, and children or young adults up to the age 20 years [4].

India is a representative example. A teaching hospital in Assam reported 101 cases of diphtheria in a 5-year period of 1997-2002 [5]. Also in a tertiary care hospital in north India [6], diphtheria has reappeared. In fact, globally there were 7088 cases of diphtheria in 2008 [7], out of which 6081 cases were in India (86\%) [8]. Regarding tetanus, reports show that tetanus continues as a problem in India [9]. In fact, $22 \%$ of the total tetanuscases in the world in 2008 were from India (3714 out of 16628 cases) [7,8].

The World Health Organization (WHO) recommends three doses of triple diphtheria-tetanus-pertussis vaccine (DTP) at age of 6, 10 and 14 weeks, followed by a booster in the second year of life. To maintain the protection, a second booster of diphtheria-tetanus (DT) vaccine is recommended [10] at the preschool age of 4 to 7 years.

The Indian Universal Immunization Programme (UIP) follows the recommendation [11], although susceptibility of this age group has not been determined. Therefore, we carried out a study in which the true need for the DT booster for the pre-school children in India was investigated.

\section{Subjects and Methods}

\subsection{Set up}

The study was performed at the Immunization Clinic of the Jalna Mission Hospital, Jalna, India. The parents/ 
guardians were informed about the study, and those willing to participate gave their consent in writing. Children of 4 to 6 years of age with documented history of four timely doses of DPT vaccine given previously, and thus being eligible for the second booster, were screened. After checking eligibility of the child, a blood sample was taken for serology, and DT vaccine was administered intramuscularly in the right deltoid area. A second blood sample was collected 28 days after vaccination.

Children with known immune system disorder, malignancy or receiving immunosuppressive therapy or blood products within the previous 3 months were excluded from the study, as were those with a chronic disease, neurological disorder, allergy to any vaccine component, or history of serious adverse event following DTP vaccination.

\subsection{Vaccine}

Each $0.5 \mathrm{ml}$ dose of the DT vaccine, manufactured by Serum Institute of India Ltd, Pune (Batch No: DT 108ZA [I.P.]; expiry date: April 2009), contained $\leq 25 \mathrm{Lf}$ ( $\geq 30 \mathrm{IU})$ of diphtheria toxoid, and $\geq 5$ Lf $(\geq 40 \mathrm{IU})$ of tetanus toxoid, adsorbed in $\geq 1.5 \mathrm{mg}$ of aluminum phosphate (AlPO4), with $0.01 \%$ of thiomersal as a preservative. The vaccine was stored at $+2^{\circ} \mathrm{C}$ to $+8^{\circ} \mathrm{C}$. Storage temperature was monitored every day.

\subsection{Serology}

The blood samples were collected aseptically, and after centrifugation at 3000-5000 rpm, sera were stored in liquid nitrogen and shipped to Sahyadri Hospital, Pune for testing. All samples were stored at $-20^{\circ} \mathrm{C}$.

Anti-diphtheria and anti-tetanus antibodies were measured with the enzyme-linked immunosorbent assay (ELISA) using commercially available kits from Virion/ Serion Classic (Germany).

Protection from disease was estimated by using the following cutoff levels of specific IgG antibodies: For diphtheria, $<0.01 \mathrm{IU} / \mathrm{ml}$ (no protection), $0.01-<0.1$ $\mathrm{IU} / \mathrm{ml}$ (minimal protection), $\geq 0.1 \mathrm{IU} / \mathrm{ml}$ (safe protection) and $>1.0 \mathrm{IU} / \mathrm{ml}$ (long-term protection). The same for tetanus was $<0.1 \mathrm{IU} / \mathrm{ml}$ (no protection), $\geq 0.1$ $\mathrm{IU} / \mathrm{ml}$ (sufficient protection) and $>1 \mathrm{IU} / \mathrm{ml}$ (long term protection). In GMT calculations, all negative values were assumed to be zero and were excluded from analysis.

\subsection{Safety Evaluation}

Vaccinees were closely monitored for 15 minutes for any immediate adverse reaction. For later potential event, the parents/guardians were trained by the site personnel to document those in diary cards, which they obtained from the vaccinator. During the next 28 days, the child was asked to attend a visit three more times. At each visit, the history of adverse events and concomitant medications was taken, data from the cards were collected, and a general physical examination was performed. The most relevant local (pain, redness, swelling, and nodule) and general reactions (fever and malaise) were specifically solicited in 7 days following vaccination, but the parents were requested to contact the study staff immediately should any serious adverse event occur during the study period. All adverse events, including solicited reactions, were graded for severity based on pre-defined criteria as 1 (mild), 2 (moderate) and 3 (severe).

A serious adverse event (SAE) was defined as one, which resulted in death, was life threatening, required hospitalization or prolongation of hospitalization, caused persistent or significant disability or incapacity, or was otherwise medically important. Medical judgement was used for causality assessment.

\subsection{Statistical Analysis}

Number of subjects with different levels of anti-diphtheria and anti-tetanus antibodies was expressed in number (n) and percentages (\%). Pre- and post vaccination seroprotection rates were compared using ' $Z$ ' test. Wilcoxon's Signed Rank test was used to compare the pre and post-vaccination geometric mean titres (GMTs). Exact Binomial 95\% Confidence Interval were calculated for pre- and post vaccination seroprotection rates, GMTs and percentages of adverse events. All $\mathrm{P}$ values $\leq 0.05$ were considered significant. Adverse events were analyzed on the intention-to-treat (ITT) basis, whereas the serological data were analyzed as per protocol.

\subsection{Ethical Aspects}

All study documents were approved by the Ethics committee of Sahyadri Speciality Hospital Pune. The study was conducted according to the principles of the Declaration of Helsinki, International Conference on Harmonization Good Clinical Practices guidelines, and the regulatory and ethical guidelines of India.

Parents/guardian were given an information sheet and consent form in Marathi and Hindi languages. After reading the sheet, approval was given by signature. The study doctors answered to all potential questions.

\section{Results}

Of the total of 244 children primarily enrolled in the study, 21 subjects were inappropriately enrolled, and 3 subjects withdrew from the project. Eleven serum samples were lost by leakage or breakage of tubes. As one of the lost samples was of a withdrawn subject, 210 children were finally analyzed. 
The gender distribution was even, the mean age was 5 years, and the mean height and weight was $102 \mathrm{~cm}$ and $18 \mathrm{~kg}$, respectively.

Initially, $30 \%$ of the subjects were not adequately protected against diphtheria, because $18 \%$ were deemed susceptible and $12 \%$ had minimum protection. (Table 1) Against tetanus, $14 \%$ of subjects were not protected at all. (Table 2).

The DT booster elicited seroprotection against diphtheria in $98 \%$ of the subjects, and against tetanus in all subjects. (Table 1, 2) When examined proportionally, the change was highly significant $(\mathrm{p}<0.05)$ for both antibodies. (Table 3) Post vaccination GMTs were significantly higher as compared to pre-vaccination. $(\mathrm{p}<0.05)$ (Table 4).

Our safety ITT analysis on 223 vaccinees found pain in $42 \%$, redness $(\leq 25 \mathrm{~mm})$ in $29 \%$, and swelling $(\leq 35$ $\mathrm{mm}$ ) in $30 \%$. Most reactions were mild in severity and lasted for 1-2 days. Fever was reported in $4 \%$ of subjects, temperature ranging from 38 to $39^{\circ} \mathrm{C}$. Fever lasted 1-5 days. A few vaccinees were treated with paracetamol. All reactions resolved without sequelae. (Table 5)

Some unsolicited adverse events were also reported. Weakness, giddiness, rash, enteric fever, anemia and worm infestation were observed in one subject each, three children vomited, and signs of an upper respiratory tract infection were observed in nine vaccinees. Cold was observed in two cases, cough and cold in three cases and cough in four cases. All these events were taken as causally unrelated to the vaccine. A 5year-old male child was hospitalized 8 days post-vaccination due to fever. Widal test disclosed enteric fever, and an antimicrobial medication led to full recovery. This case, too, was deemed unrelated to vaccine.

\section{Discussion}

Large-scale vaccinations against diphtheria in early in-

Table 1. Anti-diphtheria antibody (IgG) levels before and one month after DT vaccination.

\begin{tabular}{lcccc}
\hline & \multicolumn{4}{c}{ Number of subjects } \\
\cline { 2 - 5 } $\begin{array}{l}\text { Anti-diphtheria antibody } \\
\text { (IgG) levels }\end{array}$ & $\begin{array}{c}\text { Pre-vaccination } \\
(\mathrm{N}=210)\end{array}$ & $\begin{array}{c}\text { Post-vaccination } \\
(\mathrm{N}=210)\end{array}$ \\
\cline { 2 - 5 } & $\mathrm{n}$ & $\%$ & $\mathrm{n}$ & $\%$ \\
\hline $\begin{array}{l}\text { No Protection } \\
(<0.01 \mathrm{IU} / \mathrm{ml})\end{array}$ & 38 & 18 & 4 & 2 \\
$\begin{array}{l}\text { Minimal Protection } \\
(0.01-<0.1 \mathrm{IU} / \mathrm{ml})\end{array}$ & 26 & 12 & 0 & 0 \\
$\begin{array}{l}\text { Safe Protection }(\geq 0.1 \mathrm{IU} / \mathrm{ml}) \\
\text { Long Term Protection } \\
(>1.0 \mathrm{IU} / \mathrm{ml})\end{array}$ & 146 & 70 & 206 & 98 \\
\hline
\end{tabular}

Table 2. Anti-tetanus antibody (IgG) levels before and one month after DT vaccination.

\begin{tabular}{lcccc}
\hline & \multicolumn{4}{c}{ Number of subjects } \\
\cline { 2 - 5 } & $\mathrm{n}$ & $\%$ & $\mathrm{n}$ & $\%$ \\
\cline { 2 - 5 } $\begin{array}{l}\text { Anti-tetanus antibody } \\
\text { (IgG) levels }\end{array}$ & $\begin{array}{c}\text { Pre-vaccination } \\
(\mathrm{N}=210)\end{array}$ & $\begin{array}{c}\text { Post-vaccination } \\
(\mathrm{N}=210)\end{array}$ \\
\cline { 2 - 5 } & 30 & 14 & 0 & 0 \\
\hline $\begin{array}{l}\text { No Protection } \\
(<0.1 \mathrm{IU} / \mathrm{ml})\end{array}$ & 180 & 86 & 210 & 100 \\
$\begin{array}{l}\text { Sufficient Protection } \\
\begin{array}{l}\geq 0.1 \mathrm{IU} / \mathrm{ml}) \\
\text {-Long Term Protection } \\
(>1.0 \mathrm{IU} / \mathrm{ml})\end{array}\end{array}$ & 64 & 30 & 155 & 74 \\
\hline
\end{tabular}

Table 3. Seroprotection rate before and one month after DT vaccination.

\begin{tabular}{lccc}
\hline $\begin{array}{l}\text { Vaccine } \\
\text { Components }\end{array}$ & \multicolumn{2}{c}{ Seroprotection Rate $(\% \& 95 \% \mathrm{CI})$} & $\begin{array}{c}\text { P value* } \\
\text { (Pre Vs } \\
\text { Post) } \\
\text { Praccination }\end{array}$ \\
\hline Diphtheria & $\begin{array}{c}70 \% \\
\text { Post-vaccination } \\
(\mathrm{N}=210)\end{array}$ & $\begin{array}{c}98 \% \\
{[63 \%-76 \%]}\end{array}$ & $\mathrm{P}<0.05$ \\
\hline Tetanus & $\begin{array}{c}86 \% \\
{[80 \%-90 \%]}\end{array}$ & $\begin{array}{c}100 \% \\
{[98 \%-100 \%]}\end{array}$ & $\mathrm{P}<0.05$ \\
\hline
\end{tabular}

*“Z” test was applied.

Table 4. Geometric mean titres before and one month after DT vaccination.

\begin{tabular}{|c|c|c|c|}
\hline \multirow{2}{*}{$\begin{array}{c}\text { Vaccine } \\
\text { omponents }\end{array}$} & \multicolumn{2}{|c|}{ GMT (IU/ml) \& $95 \%$ CI } & \multirow{2}{*}{$\begin{array}{c}\text { P value* } \\
\text { (Pre Vs Post) }\end{array}$} \\
\hline & $\begin{array}{l}\text { Pre-vaccination } \\
\quad(\mathrm{N}=210)\end{array}$ & $\begin{array}{l}\text { Post-vaccination } \\
\quad(\mathrm{N}=210)\end{array}$ & \\
\hline Diphtheria & $\begin{array}{c}0.35 \\
{[0.29-0.41]}\end{array}$ & $\begin{array}{c}2.02 \\
{[1.78-2.28]}\end{array}$ & $\mathrm{P}<0.05$ \\
\hline Tetanus & $\begin{array}{c}0.56 \\
{[0.48-0.65]}\end{array}$ & $\begin{array}{c}1.48 \\
{[1.37-1.58]}\end{array}$ & $\mathrm{P}<0.05$ \\
\hline
\end{tabular}

*Wilcoxon's Signed Rank test was applied.

fancy decreases the extent to which toxigenic Corynebacterium diphtheriae circulate in community. Thus, the opportunities for natural boosting decline, which leads to lowering antibody titres in older children and adults. Serological studies from the 1980s indicated that, with increasing age, a high proportion of individuals become susceptible to diphtheria. On the other hand, the herd effect due to high vaccination coverage $(>70 \%)$ in the juvenile population may in part explain why diphtheria outbreaks are relatively rare [3]. 
Table 5. Incidence of solicited local and systemic reactions reported during the 7-day follow-up period after vaccination. ( $\mathrm{N}=223)$.

\begin{tabular}{|c|c|c|c|}
\hline \multirow{2}{*}{\multicolumn{2}{|c|}{ Solicited reactions }} & \multicolumn{2}{|c|}{ Severity } \\
\hline & & \multirow{2}{*}{$\begin{array}{c}\begin{array}{c}\text { All } \\
\text { reactions }\end{array} \\
94\end{array}$} & \multirow{2}{*}{$\begin{array}{c}\begin{array}{c}\text { Grade } 3 \\
\text { reactions }\end{array} \\
15\end{array}$} \\
\hline Pain & $\mathrm{n}$ & & \\
\hline & $\%$ & 42 & 7 \\
\hline & CI & $36-49$ & $4-11$ \\
\hline \multirow[t]{3}{*}{ Redness } & $\mathrm{n}$ & 65 & 0 \\
\hline & $\%$ & 29 & 0 \\
\hline & CI & $23-36$ & $0-2$ \\
\hline \multirow[t]{3}{*}{ Swelling } & $\mathrm{n}$ & 66 & 0 \\
\hline & $\%$ & 30 & 0 \\
\hline & CI & $24-36$ & $0-2$ \\
\hline \multirow[t]{3}{*}{ Fever } & $\mathrm{n}$ & 8 & 0 \\
\hline & $\%$ & 4 & 0 \\
\hline & & $2-7$ & $0-2$ \\
\hline
\end{tabular}

In our study, $30 \%$ of children turned out to be inadequately protected from diphtheria and $14 \%$ were susceptible to tetanus after four doses of DTP. Thus, a booster dose at pre-school age is unquestionably indicated for this age group in India, and most likely elsewhere in the developing world. Though primary immunization against diphtheria and tetanus is supposed to give a long -lasting immunity, it does not give full protection. Outbreaks of mild diphtheria can occur among highly vaccinated persons living in crowded conditions with intense exposure [12]. Very rarely, tetanus has been reported in persons who had received primary immunization $[13,14]$. This underlines the need for booster doses as confirmed by our study.

Our results on diphtheria agree with those from Thailand where, despite infant immunization coverage exceeding 90\%, diphtheria still occurred throughout the 1990 s primarily in children $<15$ years old. The reason was obvious: no less than $25 \%$ of adults at age $20-39$ years and $14 \%$ of adolescents aged $10-19$ years lacked diphtheria antibodies [15]. In Thailand, susceptibility to diphtheria accumulated in these younger age groups, whereas in Brazil [16] a study examining the population across all ages showed an inadequate protection in $16 \%$ of the study subjects. For tetanus, the proportion was $21 \%$. These results suggest that DT boosters are likely needed throughout adult life. In many countries (e.g. Finland), a booster for decades has been recommended at ten-year intervals.

The coverage with three doses of DTP as a part of primary immunization in India is just $62 \%$ [8]. The countrywide figures for coverage with a DTP booster in the second year of life and DT boosters during the preschool age are not available but one can recognize that it must be below the DTP3 coverage. In a study in the city of Hyderabad, the coverage for primary vaccination, fourth, and fifth (DT) doses was 90\%, 60\%, and 33\%, respectively [16], clearly demonstrating that the coverage goes down for the DT booster. The coverage becomes of paramount importance since India contributes 86\% and $22 \%$ of global cases of diphtheria and tetanus, respectively $[7,8]$.

The DT booster proved highly immunogenic and sufficiently safe in virtually all vaccinees. Our results coincide with those reported from other studies [17-19].

Keeping in mind a substantial proportion of susceptibles for diphtheria and tetanus in fully vaccinated preschool age children in our study and inadequate coverage of the booster, there is a strong need to create public awareness on the importance of the booster vaccination. This is especially true since India has a large number of diphtheria and tetanus cases.

\section{Acknowledgments}

Authors thank all study participants and their parents. Authors also thank Dr Somnath Mangrule for review of manuscript.

\section{REFERENCES}

[1] I. R. Hardy, S. Dittmann and R. W. Sutter, "Current situation and control strategies for resurgence of diphtheria in newly independent states of the former Soviet Union," Lancet, Vol. 347, No. 9017, June 1996, pp. 1739-44. doi:10.1016/S0140-6736(96)90811-9v

[2] S. Dittmann, "Epidemic diphtheria in the Newly Independent States of the former USSR--situation and lessons learned," Biologicals, Vol. 25, No. 2, June 1997, pp. 179-86. doi:10.1006/biol.1997.0081

[3] A. M. Galazka and S. E. Robertson, "Diphtheria," In: C. J. L. Murray, A. D. Lopez, C. D. Mathers, Ed., The Global Epidemiology of Infectious Disease, Harvard University Press, Cambridge, 2004.

[4] A. Galazka, M. Birmingham, M. Kurian and F. L. Gasse, "Tetanus," In: C. J. L. Murray, A. D. Lopez, C. D. Mathers, Ed., The Global Epidemiology of Infectious Disease, Harvard University Press, Cambridge, 2004.

[5] R. Nandi, M. De, S. Browning, P. Purkayastha and A. K Bhattacharjee, "Diphtheria: the patch remains," The Journal of Laryngology \& Otology, Vol. 117, No. 10, October 2003, pp. 807-10.

[6] R. Lodha, N. R. Dash, A. Kapil and S. K. Kabra, "Diphtheria in urban slums in north India," Lancet, Vol. 355, No. 9199, January 2000, pp. 204. doi:10.1016/S0140-6736(99)04847-3

[7] World Health Organization, "WHO vaccine-preventable diseases: monitoring system 2009 global summary, Immunization, Vaccines and Biologicals,"2009. http://whqlibdoc.who.int/hq/2009/WHO_IVB 2009 eng. pdf. 
[8] World Health Organization, "India 2008. EPI Fact sheet," 2008.http://www.searo.who.int/vaccine/LinkFiles/EPI200 8/India08.pdf.

[9] S. Anuradha, "Tetanus in adults-a continuing problem: an analysis of 217 patients over 3 years from Delhi, India, with special emphasis on predictors of mortality," The Medical Journal of Malaysia, Vol. 61, No. 1, March 2006, pp. 7-14.

[10] "Diphtheria vaccine - WHO position paper," Weekly Epidemiological Record, Vol.81, No. 3, 2006, pp. 24-32.

[11] "Core Programme Clusters. Family and Community Health, Routine Immunization," 2011. http://www.whoindia.org/EN/Section6/Section284/Sectio n286 508.htm.

[12] C. Ohuabunwo, J. Perevoscikovs, A. Griskevica, P. Gargiullo, A. Brilla and Viksna L, et al, "Respiratory diphtheria among highly vaccinated military trainees in Latvia: improved protection from DT compared with Td booster vaccination," Scandinavian Journal of Infectious Diseases, Vol. 37, No.11-12, 2005, pp. 813-20. doi: $10.1080 / 00365540500262658$

[13] Z. Shimoni, A. Dobrousin, J. Cohen and S. Pitlik, "Tetanus in an immunised patient," British Medical Journal, Vol. 319, No. 7216, October 1999, pp. 1049.

[14] D. R. Vinson, "Immunisation does not rule out tetanus," British Medical Journal, Vol. 320, No. 7231, Febuary 2000, pp. 383.
[15] P. Tharmaphornpilas, P. Yoocharoan, P. Prempree, S. Youngpairoj, P. Sriprasert and C. R. Vitek, "Diphtheria in Thailand in the 1990s," Journal of Infectious Diseases, Vol. 184, No. 8, October 2001, pp. 1035-40 doi: $10.1086 / 323453$

[16] K. G. Divino-Goes, M. I. Moraes-Pinto, M. I. Dinelli, S. T. Casagrande, T. C. Bonetti, P. R. Andrade and L. Y. Weckx, "Prevalence of diphtheria and tetanus antibodies and circulation of Corynebacterium diphtheriae in São Paulo, Brazil," Brazilian Journal of Medical and Biological Research, Vol. 40, No. 12, December 2007, pp. 1681-7. doi:10.1590/S0100-879X2006005000184

[17] M. L. Ciofi degli Atti, S. Salmaso, B. Cotter, G. Gallo, G. Alfarone, A. Pinto, A. Bella and C. von Hunolstein, "Reactogenicity and immunogenicity of adult versus paediatric diphtheria and tetanus booster dose at 6 years of age," Vaccine, Vol. 20, No. 1-2, Octomber 2001, pp. 74-9.

[18] M. Blennow, M. Granström and A. Strandell, "Adverse reactions after diphtheria-tetanus booster in 10-year-old schoolchildren in relation to the type of vaccine given for the primary vaccination," Vaccine, Vol. 12, No. 5, April 1994, pp. 427-30. doi:10.1016/0264-410X(94)90119-8

[19] A. Mark, R. M. Carlsson and M. Granström, "Subcutaneous versus intramuscular injection for booster DT vaccination of adolescents," Vaccine, Vol. 17, No. 15-16, April 1999, pp. 2067-72. doi:10.1016/S0264-410X(98)00410-1 